\title{
Emotional Intelligence, Trust, and Functional Behavior: Longitudinal Study of Achievement Approach to Leadership Emergence
}

\author{
Kihwan Kim \\ Kean University \\ Joseph Kim \\ New York University \\ Justin Antonio \\ Kean University \\ Janell Laws \\ Kean University
}

Leadership emergence refers to the phenomenon where an individual voluntarily takes a leadership role even when there is no designated leader. There have been many studies that investigated the antecedents of leadership emergence but few studies have investigated the integrative process of leadership emergence. Based on the achievement approach to leadership emergence, the current study attempts to explore how an individual's trait, state, and behavior are related to leadership emergence. The study found that an individual with high emotional intelligence is more likely to emerge as a leader by perceiving trust and showing task behaviors. We collected longitudinal data from 171 participants (43 groups) who played a business simulation game as a group task for 11 weeks. The data analysis revealed that emotional intelligence is positively related to trust, which in turn has a positive impact on task behavior. Additionally, task behavior has a positive impact on leadership emergence. In the study we discussed implications, limitations, and future research issues.

Keywords: achievement approach to leadership emergence, emotional intelligence, trust, functional behavior, longitudinal study

\section{INTRODUCTION}

Since the importance of teamwork is highlighted in team and organization performance, many scholars have investigated the factors that might contribute to effective teamwork in organizations. Among the numerous factors studied, leadership structure within the team is one of the most crucial contributors.

In a general sense, leaders can be classified into two types: appointed and emergent. Appointed or formal leaders command their power from positions of authority while emergent leaders are validated through an informal process of acceptance by other members (Hollander, 1974). Leadership emergence is 
defined as "being perceived as leaderlike" (Kaiser et al., 2008: 97). Emergent leaders are individuals in a team who are perceived by other members to either possess certain traits or engage in certain behaviors associated with leadership (Bergman et al., 2014).

In past studies that compared the effectiveness of appointed and emergent leadership, the results often demonstrated that emergent leadership yield superior performance compared to appointed leadership in many contexts. These superior outcomes of emergent leadership led to studies on the antecedents that contribute to leadership emergence development.

But even though the literature has substantially contributed to understanding the process of leadership emergence development, the findings are fractional and scattered; few researchers have tried to develop a comprehensive model to describe the leadership emergence process. In addition, most studies used crosssectional data which made it hard to examine the developing process over extended periods.

Recently, Paunova (2015) proposed a conceptual model that is called the Achievement Approach to Leadership Emergence. This model analyzed the antecedent variables of leadership emergence and classified them into three categories-trait, state, and behavior. The model was carefully designed so that leadership emergence relies largely on traits, mediating processes (state), and behaviors to explain who is perceived as a leader (i.e., trait $\rightarrow$ state $\rightarrow$ behavior $\rightarrow$ perception). This model is in line with prevailing leadership-effectiveness theories (Yukl, 2013; Zaccaro, et al., 2004) and sheds new light on the leadership emergence literature by suggesting a comprehensive model that reflects the dynamic process of leadership emergence. Paunova's model (2015) explained the development process of leadership emergence by connecting the scattered, fragmental findings of past studies.

However, despite the value and potential of the model, there have been few studies to validate this model empirically. The purpose of the current study is to validate the suggested model with specific variables that match trait, state, and behavior. Based on the model, we investigate how emotional intelligence, over time, contributes to the development of leadership emergence via the perception of team trust and functional behaviors. Our study brings a unique contribution to the leadership emergence literature by elaborating and testing the leadership emergence process using longitudinal data. Also, our study will explore how antecedent variables interact with each other, leading to leadership emergence over time.

The following sections of this article include a literature review of major variables and hypotheses development. A methodology section follows, along with a description of the statistics and results. The discussion of the results precedes a conclusion, limitations, future research, and practical implications section.

\section{LITERATURE REVIEW}

\section{Individual Leadership Emergence Process}

The literature on leadership emergence has identified numerous antecedents, helping to understand what causes leadership emergence. However, there is a lack of studies that investigate how the antecedent variables interact with each other and how leadership emerges as a result of those interactions. In particular, there have been limited studies to identify and explain the process mechanism of leadership emergence.

The Achievement Approach to Leadership Emergence (Paunova, 2015) states that leadership emergence relies largely on the interaction of the person's traits, mediating processes (states), and behaviors over time. According to the model, the antecedents of leadership emergence can be classified into trait, state, and behavior. The model describes how each category relates to the other categories: trait variables lead to state variables, which in turn lead to behavior variables, ultimately which influence leadership emergence. The major theoretical implication of the model is that it classifies leadership emergence into three categories - trait, state, and behaviors. This approach shed new light on existing leadership emergence literature as it integrated and organized the antecedents of leadership emergence.

Traits refer to the unique characteristics of an individual and encompass the broad range of aspects that can describe an individual such as attitude, personality, emotion, intelligence, etc. In a teamwork setting, traits have been considered as one of the crucial factors that predict both individual and team performance. In particular, leadership emergence literature highlighted the big five personalities (Judge et al., 2002; Ilies 
et al., 2004), intelligence (Bass, 1990; Judge et al., 2004), emotional stability (e.g., Côté et al., 2010; Kellet et al., 2002, 2006), and social intelligence (Ensari et al., 2011) as crucial traits that enable an individual to emerge as a leader.

The State is often called an emergent state or a mediating process. Within a team, an individual would develop both an emotional and cognitive state, which is caused by individual traits or interactions with team members. Scholars have identified prominent emergent states that might appear during the leadership emergence process; examples include motivation to lead (Chan \& Drasgow, 2001), the perception of trust (Baker et al., 2016; Drescher et al., 2014, Kildeff et al., 2017), and empathy and perspective-taking (Wolff et al., 2002).

The last process stage is Behavior, which refers to an individual's functional or dysfunctional behaviors within a team or group. In a team setting, the team members' behaviors are understood in terms of social and task behaviors (Bergman et al., 2014, Gronn, 2002). Social behaviors refer to team members' activities that promote team bondage and cohesion such as communication, support, and encouragement (Bergman et al., 2014, Gronn, 2002). Meanwhile, task behaviors describe team members' activities that facilitate goal achievement such as knowledge sharing, technical contribution (O'Mahony \& Ferraro, 2007), organization building (O'Mahony \& Ferraro, 2007), and boundary spanning (Fleming \& Waguespack, 2007).

Table 1 presents past literature on trait, state, and behavior.

\section{TABLE 1}

\section{PAST LITERATURE ON TRAIT, STATE, AND BEHAVIOR}

\begin{tabular}{|l|l|}
\hline & \multicolumn{1}{c|}{ Past studies } \\
\hline Trait & $\begin{array}{l}\text { Big five personality (Judge et al., 2002; Ilies et al.2004) } \\
\text { Intelligence (Bass, 1990, Judge et al., 2004) } \\
\text { Emotional ability (e.g., Côté et al., 2010; Kellet et al., 2002, 2006) } \\
\text { Social intelligence/skills (Ensari et al., 2011). }\end{array}$ \\
\hline State & $\begin{array}{l}\text { Motivation to lead (Chan \& Drasgow, 2001) } \\
\text { Achievement and affiliation oriented (Sorrentino \& Field, 1986) } \\
\text { The perception of trust (Baker et al., 2016; Drescher et al., 2014, Kildeff et al., 2017) } \\
\text { Empathy/Perspective Taking (Wolff et al., 2002) }\end{array}$ \\
\hline Behavior & $\begin{array}{l}\text { Functional behavior (Day et al., 2004; Fleishman et al., 1991; Zaccaro et al., 2001).) } \\
\text { Task and social-oriented behavior (Bergman et al., 2014, Gronn, 2002) } \\
\text { Technical contributions counts (O'Mahony \& Ferraro, 2007) } \\
\text { Organization-building (O'Mahony \& Ferraro, 2007) } \\
\text { Boundary-spanning (Fleming \& Waguespack, 2007) }\end{array}$ \\
\hline
\end{tabular}

Another critical theoretical contribution of the model is that it proposed the process of leadership emergence development as a relationship among three categories. The model claimed that leadership emergence initiates from the traits of group members. For example, individuals with special traits such as personality or emotional capability are more likely to emerge as a leader (e.g., Côté et al., 2010; Judge et al., 2002; Ilies et al., 2004; Kellet et al., 2002, 2006). However, although the trait plays a crucial role in leadership emergence, it explained limited variances of leadership emergence. Often, the traits of individuals and their interactions with other team members are likely to develop emotional or cognitive states including the motivation to lead, achievement/affiliation needs, trust, and empathy/perspective-taking (e.g., Chan \& Drasgow, 2001; Sorrentino \& Field, 1986; Baker et al., 2016; Drescher et al., 2014, Kildeff et al., 2017). The emerged states drive individuals to show various behaviors such as positive or negative ones, social behaviors, and task behaviors. In particular, social and task behaviors are a strong cue of leadership emergence (e.g., Bergman et al., 2014, Gronn, 2002; O'Mahony \& Ferraro, 2007). When an individual demonstrates functional team behavior including both social and task behavior, team members are likely to award the individual by endowing a leader-like status. Figure 1 illustrates the process of Achievement Approach to Leadership Emergence. 


\section{FIGURE 1 \\ ACHIEVEMENT APPROACH TO LEADERSHIP EMERGENCE}

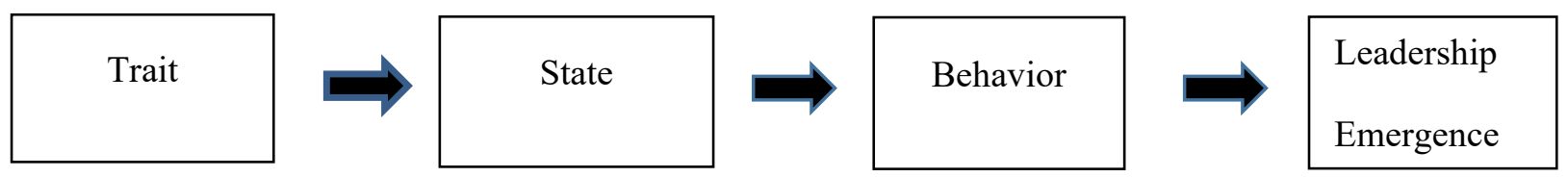

\section{HYPOTHESES DEVELOPMENT}

\section{Emotional Intelligence and Trust}

Goleman (1995) suggested that emotional intelligence encompasses five characteristics: self-control, self-awareness, motivation, social skill, and empathy. Later, Mayer and Salovey (1997) refined the construct of emotional intelligence and discussed four sub-constructs of emotional intelligence: 1) reflective regulation of emotions to promote emotional and intellectual growth, 2) understanding and analyzing emotions, and employing emotional knowledge, 3) emotional facilitation of thinking, and 4) perception, appraisal, and expression of emotion.

Emotional intelligence can have an impact on a person's affective and cognitive states. For example, Bar-On (1997) found that emotional intelligence can help people successfully cope with environmental demands and pressures. This is because people with high emotional intelligence are better able to control or redirect disruptive impulses and moods, so they feel more comfortable with ambiguity and are open to change (Goleman, 1998). Additionally, emotional intelligence is closely related to social skills that facilitate effective teamwork (Salovey \& Mayer 1990; Mayer \& Salovey 1997; Goleman 1998). For example, people with high emotional intelligence have greater proficiency in managing relationships and building networks, have greater ability to find common grounds, and are assertive at communicating their ideas, goals, and intentions to build rapport (Goleman, 1998; Kim, 2010; Kim et al., 2014).

EI facilitates group development because effective teamwork begins with knowing each other's strengths and weaknesses and leveraging those strengths (Bar-On, 1997). In a similar vein, Druskat and Wolf (2001) proposed that group emotional intelligence helps develop team trust and a sense of shared identity. Thus, EI plays a critical role in nurturing team effectiveness, which leads to better decision making, development of creative solutions, and higher productivity. Furthermore, several empirical studies have found that group emotional intelligence was positively related to team trust (Barczak et al., 2010), team process effectiveness, and goal focus (Jordan et al. 2002).

Emotionally intelligent individuals are also more likely to better manage emotional fluctuations and facilitate positive emotional reactions in themselves and others (Jordan et al., 2002). This is critical since positive emotions lay the groundwork for the development of trust, an experience characterized by mutual identification and the shared value of the social exchange (Jones \& George, 1998). Empirical studies demonstrated that emotional intelligence fostered trust among team members (Black et al., 2019) and between negotiation partners (Kim, 2010).

In sum, a team with highly emotionally intelligent members is more likely to develop trust among team members. Based on the discussion above, we suggest the following hypothesis:

\section{Hypothesis 1: Emotional Intelligence will have a positive association with Trust.}

\section{Trust and Functional Team Behavior}

Trust is defined as the willingness of individuals to expose themselves or become vulnerable to others (Butler, 1999). Alternatively, trust can be viewed as a person's expectation that another person has good intention to achieve better group performance-requiring an interpersonal relationship as a prerequisite condition (Dirks, 1999, 2000). This view sets a relevant foundation that trust is developed from an interaction between an individual and other people in a team setting, and in that interdependent relationship, each party sets expectations about the counterpart's performance relative to the degree of their trust. For 
that reason, Jones and George's (1998) interactionist model frames trust as a dynamic, evolving state in which values, attitudes, moods, and emotions simultaneously interact to produce an overall sense of trust or distrust. Thus, trust is in part built on emotional expectations and bonds between individuals.

Team literature has evidenced that trust is a strong predictor of a positive team process. Mach et al. (2010), for example, found that team members' trust, in both their teammates and their leader, was positively related to both social and task cohesion. Furthermore, trust is a strong predictor of helping behaviors, organizational citizenship behavior (OCB), and team commitment.

In sum, when an individual develops trust with other members, he or she is more likely to show the team behaviors such as engaging in group work, making a commitment, and achieving the group goals. In contrast, a lack of trust in other members will demotivate people to make a commitment to group tasks and goals and communicate with others. Based on the discussion above, we proposed the following hypothesis.

\section{Hypothesis 2: Trust in team members will have a positive association with Functional Team Behavior.}

\section{Functional Team Behavior and Leadership Emergence}

A functional approach to leadership emergence suggests that there is a set of leadership behaviors required for groups to function effectively. Those who perform these behaviors are rewarded with higher leadership status (Lord, 1977). This approach emphasizes how one or more members of a group attains leadership status by satisfying group needs, getting things done, and fulfilling important group functions. Hiller et al. (2006) developed a four-dimensional typology to explain the enactment of various members under team leadership. They explained planning and organizing, problem-solving, support and consideration, and developing and mentoring as the four functions within teams.

Hollander (1992) did a review of literature on emergent leadership and found that task-focused behavior and relation-focused behavior were both important to be selected as leaders. Seers et al. (2003) observed that the most respected team members took the role of task leader and the most liked team member occupied the social or relational leader role. Bergman et al. (2014) found that social and task behaviors were related to leader emergence over time. This suggests that both social and task-oriented behaviors are needed by the group and that individuals who perform both types of these behaviors are seen by others as indicative of leadership. However, team members perceived task behavior to be relatively more important than social behavior to leader emergence over time.

In sum, when an individual shows functional team behavior that contributes to the achievement of team purpose or promotes the bondage of team members, other members will appreciate the contribution of the team member and be more dependent on his or her guidance to achieve team goals. This process will naturally make the member develop a leader-like status within the team. Based on the discussions in this section, we proposed the following hypothesis:

Hypothesis 3: Functional Team Behavior will have a positive association with Leadership Emergence.

\section{RESEARCH METHODOLOGY}

\section{Participants}

Business majoring seniors at a large-sized private university in the U.S. participated in the experiment and survey. During the study, the participants played an online business simulation as a group. Each team consisted of 4-5 members and a total of 171 students on 43 teams were involved in this longitudinal study. For each team, no one was assigned as a leader. Of the participants, 46 percent were male and 54 percent female. The average age of the participants was 21.2 years $($ s.d. $=1.6)$, and the average self-reported grade point average (GPA) was 3.01 (s.d. =0.32). Regarding ethnicity, students self-reported as White $(86.8 \%)$, Hispanic (6.7\%), African American (5.4\%), Asian (3.1\%), and other (0.8\%). 


\section{Group Task}

Participants were assigned to teams to compete in a business simulation game as a requirement for their course. Each team had four or five members and managed a small start-up company, each with the same resources at the beginning of the competition. For eleven rounds, representing 11 weeks, the teams made decisions in R\&D, Marketing, Production, and Finance. After each round, the simulation game produced various outcomes such as profit, stock price, market share, and debt ratio which reflected team performances. The simulation mimics the general processes of running a manufacturing corporation whose key decisions should bring bigger profits to the company in a competitive environment. Thus, participants strived to make a bigger profit each round and beat its competitors. The result of the simulation accounted for $20 \%$ of student's final grades. Thus, students were motivated to make substantial efforts in the game.

During the experiment, we collected data at three different time points. The participants played the games for 11 rounds (weeks). Each round is equivalent to one week. We collected the data for emotional intelligence and trust after round \#3 (T1), functional team behavior after round \#7 (T2), and leadership emergence after round \#11 (T3).

\section{Measures}

\section{Emotional Intelligence}

We measured the participants' perceptions of their own emotional intelligence using the scale developed by Law et al. (2004, $\alpha=88$; the current study $\alpha=.81$ ). The scale has 16 items and reflects four dimensions of emotional intelligence: Self-emotion appraisal, Others' emotion appraisal, Use of emotion, and Regulation of emotion. The items were assessed on a five-point Likert scale, with " 1 " representing "strongly disagree" and "5" representing "strongly agree."

\section{Trust}

The perception of trust of the team members was measured by using an 11-item scale developed by McAllister $(1995, \alpha=0.84$; the current study $\alpha=0.91)$. This scale measured each member's perception of trust in the other team members. The participants responded to the questions using a five-point Likert scale, with " 1 " representing "strongly disagree" and " 5 " representing "strongly agree".

\section{Functional Team Behavior}

We measured the participant's team behavior using a peer evaluation survey embedded in the simulation game. The survey asked for other team members' contributions to the group task in four areas: task preparation, task monitoring, task execution, and task adjustment. The score of each team member was calculated by aggregating the scores of other members' evaluations; the score was generated automatically by the system. The participants responded to the questions using a five-point Likert scale, with "1" representing "strongly disagree" and "5" representing "strongly agree". We calculated the functional team behavior score for each individual by averaging other team members' evaluation scores.

\section{Leadership Emergence}

Leadership emergence was assessed using a three-item scale developed by Kent and Moss (1990). An interesting feature of this instrument is that it allows for the assessment of both self-perception of leader emergence and group perceptions. We used the following measure(s): "Please rate the extent to which you and each member of your group (1) assumed a leadership role, (2) led the conversation, and (3) influenced group goals and decisions". The participants responded to the questions using a five-point Likert scale, with "1" representing "strongly disagree" and " 5 " representing "strongly agree". We calculated the leadership emergence score for each individual by averaging other team members' scores and their own scores.

\section{DESCRIPTION OF STATISTICS RESULTS}

Since we collected self-reported data for emotional intelligence, trust, task behavior, and leadership emergence, there might exist the problem of common method bias in our collected data. To test for the 
presence of a common method bias, Podsakoff and his colleagues (2003) recommended a one-factor test; in factor analysis, one factor should not explain the variance across all items. If that is the case, the data set has a common method bias. The factor analysis result indicated that the principal factor explained 21.5 percent of the variance. If no single factor explained more than 50 percent of the total variance, then a common method bias is likely not an issue (Podsakoff and Organ, 1986). Table 2 presents the descriptive and correlation analysis outcomes.

TABLE 2

DESCRIPTIVE AND CORRELATION ANALYSIS

\begin{tabular}{lllllllllll}
\hline & Mean & S.D & 1 & 2 & 3 & 4 & 5 & 6 & 7 & 8 \\
\hline 1.Gender & 1.51 & .50 & & & & & & & & \\
2. Age & 24.45 & 5.01 & .09 & & & & & & & \\
3. Race & 3.31 & .35 & .05 & -.03 & & & & & & \\
4. GPA & 1.90 & 1.08 & .13 & .09 & $-.24^{* *}$ & & & & \\
5. Emotional & 3.48 & 1.36 & .03 & .09 & .04 & $.20^{* *}$ & & & & \\
Intelligence & & & & & & & & & & \\
6. Trust & 3.34 & 1.71 & -.13 & -.07 & .12 & -.10 & $.32^{* *}$ & & & \\
7. Self-efficacy & 3.44 & 1.70 & $-.20^{* *}$ & -.12 & .09 & -.02 & $.33^{*}$ & $.80^{* *}$ & & \\
8. Performance & 3.66 & 1.67 & .05 & -.09 & .04 & -.03 & $.35^{* *}$ & $.27^{* *}$ & $.19^{*}$ & \\
9. Leadership & 3.79 & .95 & .05 & -.14 & $.19^{*}$ & .13 & $.20^{* *}$ & $.16^{*}$ & .06 & $.28^{* *}$ \\
\hline$*<.05, * *<.01$ & & & & & & & & & &
\end{tabular}

\section{Hypotheses Test}

To test the reciprocal relationship between variables, we employed a time-lagged design study. We collected variable data at three different points in the study. Path analysis was conducted using SmartPLS3 with 5000 re-samples (Peng \& Lai, 2012; Hair et al., 2012). The results were presented in Figure 2.

FIGURE 2

\section{PATH ANALYSIS OUTCOME}

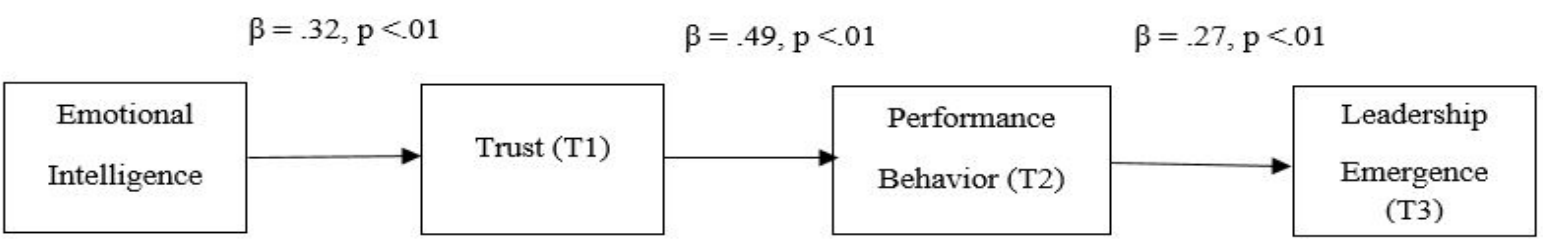

Hypothesis 1 predicted that emotional intelligence is positively related to trust. Figure 2 indicated that emotional intelligence (T1) has a significant relationship with trust $(\beta=.32, \mathrm{p}<.01)$ in $\mathrm{T} 1$. Therefore, hypothesis 1 that predicted the relationship between emotional intelligence and trust was supported.

Hypothesis 2 predicted that trust is positively related to functional team behavior. According to Figure 2 , trust in $\mathrm{T} 1$ had a significantly positive relationship with performance behavior $(\beta=.49, \mathrm{p}<.01)$ in $\mathrm{T} 2$. Therefore, the result indicated that hypothesis 2 was supported.

Hypothesis 3 proposed that performance behavior is positively related to leadership emergence. Figure 2 illustrated that performance behavior in $\mathrm{T} 2$ had a significantly positive relationship with leadership emergence $(\beta=.27, \mathrm{p}<.01)$ in T3. Thus, the result demonstrated that hypothesis 3 was supported. 


\section{DISCUSSION}

\section{Findings}

The current study investigated the model of Achievement Process of Leadership Emergence using longitudinal data analysis. The Achievement Process to Leadership Emergence is the integrative model that explains the processes of leadership emergence by identifying four stages - trait, state, behavior, and leadership emergence. Based on this model, we proposed that emotional intelligence leads to leadership emergence via trust and functional behavior.

The current study has strengths in research methodology. We used longitudinal data to test the proposed hypotheses, collecting variables at three different times. Longitudinal data is appropriate when testing the development process of leadership emergence over time and helps avoid reverse causal relationship issues. Also, in the measurement of functional behavior and leadership emergence we collected data from other members' evaluations rather than self-reported measurement, securing more objectivity in the measurement.

The data analysis revealed that our study validated the Achievement Process to Leadership Emergence model. First, we found that emotional intelligence is positively associated with the perception of trust. Since highly emotional intelligent individuals are good at communicating with other people and develop rapport quickly, they are more likely to develop trust in other team members. This finding is aligned with past studies on emotional intelligence and trust (e.g., Black et al., 2019; Kim, 2010).

Additionally, another finding of this study is that the perception of team trust leads to show functional team behaviors. When an individual develops trust in team members, he or she will feel motivated to show commitment to the group task because they expect other members to also contribute to the group work. In contrast, if a team member does not trust in other team members, he or she will be hesitant to show commitment to the group task because they fear being ripped off by other members.

Furthermore, we found that team functional behavior was positively related to leadership emergence. When a team member makes a significant contribution to the task achievement, he or she will be considered a leader by other members. In particular, when achieving goals or meeting deadlines is critical for the team's success, task behavior is more valued than other behaviors.

\section{Theoretical Implications and Future Research Issues}

The current study raised several valuable theoretical implications and provide future research issues. Although the literature on leadership emergence extensively investigated the antecedents of leadership emergence, there has been a dearth of study to explore an integrative model that explains the development process of leadership emergence. However the Achievement Approach to Leadership Emergence model (Paunova, 2015) sheds new light on understanding the process of leadership emergence. It classifies the antecedents into three developing stages - trait, state, and behaviors. There needs more research on leadership emergence from this approach. In particular, it will be valuable research to test the model empirically with many different variables at each stage.

The current study tested only one variable in each stage - emotional intelligence for the trait stage, trust for the state stage, and functional team behavior for the behavior stage. Through the discussion of the literature, we identified numerous variables at each stage. For example, personality (Judge et al., 2004), intelligence, emotional ability, and social intelligence/skills were identified for the trait stage. Motivation to lead, achievement and affiliation oriented, perspective-taking, empathy (Wolff et al., 2002), perception of trust (Drescher et al., 2014), psychological safety (Liu et al., 2014), and positive affective tone were identified at the state stage. Functional behavior (Day et al., 2004; Fleishman et al., 1991; Zaccaro et al., 2001), task and social-oriented behavior (Bergman et al., 2014, Gronn, 2002), technical contributions (O'Mahony \& Ferraro, 2007), organization-building (O'Mahony \& Ferraro, 2007), and boundary-spanning were identified at the behavior stage. Future research needs to test the Achievement Process Model with other potential variables at each stage.

Chan and Dragsow (2001) discussed that an individual's motivation to lead mediates between individual differences (i.e., ability, traits, and values) and leader behaviors. In our study, we didn't test the mediating effects that might exist among the variables since our main purpose is to validate the Achievement 
Approach to Leadership Emergence model. However, the model implies the potential of the mediation effect among variables. For example, one case is the mediation effect of state variables on the relationship between trait and behavior and another case is the mediation effect of the behavior variables on the relationship between the state variable and leadership emergence. Future research needs to examine the potential mediating relationships embedded in the model.

\section{Limitations}

This study is not without limitations. First, the participants in the current study were senior students with a business major in the mid-sized public university in the east coast area in the U.S. Thus, it needs to be careful in generalizing the result of the current study to other populations.

Second, our research employed an experimental design where the participants played a simulation game as the team task. Playing a simulation game provides many different aspects from the team task in the real situation thus the simulation game cannot fully reflect the dynamics of the development of leadership emergence. However, the simulation game was a course requirement of the senior capstone class and its simulation game outcome accounted for $20 \%$ of the total class grade. Participants were motivated to do their best in the game.

Third, we measured emotional intelligence and trust concurrently. The path analysis result demonstrated the influence of emotional intelligence on trust. Although this finding is consistent with past literature (e.g., Black et al., 2019; Kim, 2010), there is a possibility of a reverse causal relationship between emotional intelligence and trust since the two variables were measured at the same time. In future studies, it would be beneficial to investigate this relationship using data collected at different times.

Lastly, most variables were measured by a self-reported survey. This can cause the issue of common method bias. Following the recommended method, we did a one-factor test (Podsakoff et al., 2003) to investigate the existence of common method bias. The outcome demonstrated there is a low risk of the common method. However, in the future, to avoid this issue, it needs to collect data from various sources, not one source.

\section{CONCLUSION}

The model of the Achievement Approach to Leadership Emergence sheds new light on leadership emergence literature by elaborating the development process of leadership emergence. Adopting this approach, our study validated the model using longitudinal data; emotional intelligence leads to the development of the leadership emergence via trust and functional team behavior over time. The current study raised many valuable theoretical implications and future research issues. In particular, a better understanding of the leadership emergence process will benefit managers who consider and adopt a selfmanaged team structure, bring in superior team performance.

\section{REFERENCES}

Baker, S., Mathis, C., Stites-Doe, S., \& Javadian, G. (2016). The role of trust and communication in fostering followers' self-perceptions as leaders. Journal of Managerial Issues, 28(3/4), 210-230.

Bar-On, R. (1997). The Emotional Intelligence Inventory (EQ-I): Technical Manual. Multi Health Systems, Toronto, Canada.

Bass, B.M. (1990). The Bass \& Stogdill's handbook of leadership: Theory, research, and managerial applications. Free Press.

Barczak, G., Lassk, F., \& Mulki, J. (2010). Antecedents of team creativity: An examination of team emotional intelligence, team trust and collaborative culture. Creativity and Innovation Management, 19, 332-345.

Bergman, S.M., Small, E.E., Bergman, J.Z., \& Bowling, J.J. (2014). Leadership emergence and group development: A longitudinal examination of project teams. Journal of Organizational Psychology, 14(1), 111-126. 
Black, J., Kim, K., Rhee, S., Wang, K., \& Satchuchawan, S. (2019). Self-Efficacy and Emotional Intelligence: Influencing Team Cohesion to Enhance Team Performance. Team Performance Management, 25(1), 100-119.

Butler, J.K. (1999). Trust expectations, information sharing, climate of trust, and negotiation effectiveness and efficiency. Group \& Organization Management, 24(2), 217-238.

Chan, K.Y., \& Drasgow, F. (2001). Toward a theory of individual differences and leadership: Understanding the motivation to lead. Journal of Applied Psychology, 86(3), 481-498.

Colbert, A.E., Judge, T.A., Choi, D., \& Wang, G. (2012). Assessing the trait theory of leadership using self and observer ratings of personality: The mediating role of contributions to group success. Leadership Quarterly, 23(4), 670-685.

Côté, S., Lopes, P.N., Salovey, P., \& Miners, C.T.H. (2010). Emotional intelligence and leadership emergence in small groups. Leadership Quarterly, 21(3), 496-508.

Day, D.V., Gronn, P., \& Salas, E. (2004). Leadership capacity in teams. Leadership Quarterly, 15(6), $857-880$.

Dirks, K.T. (1999). The effects of interpersonal trust on work group performance. Journal of Applied Psychology, 84(3), 445-455.

Dirks, K.T. (2000). Trust in leadership and team performance: Evidence from NCAA basketball. Journal of Applied Psychology, 85(6), 1004-1012.

Drescher, M.A., Korsgaard, M.A., Welpe, I.M., Picot, A., \& Wigand, R.T. (2014). The dynamics of shared leadership: Building trust and enhancing performance. Journal of Applied Psychology, 99(5), 771-783.

Druskat, V.U., \& Wolff, S.B. (2001). Building the emotional intelligence of groups. Harvard Business Review, 79(3), 80-90.

Ensari, N., Riggio, R.E., Christian, J., \& Carslaw, G. (2011). Who emerges as a leader? Meta-analyses of individual differences as predictors of leadership emergence. Personality and Individual Differences, 51(4), 532-536.

Fleishman, E.A., Mumford, M.D., Zaccaro, S.J., Levin, K.Y., Korotkin, A.L., \& Hein, M.B. (1991). Taxonomic efforts in the description of leader behavior: A synthesis and functional interpretation. The Leadership Quarterly, 2(4), 245-287.

Fleming, L., \& Waguespack, D.M. (2007). Brokerage, boundary spanning, and leadership in open innovation communities. Organization Science, 18(2), 165-180.

Goleman, D. (1995). Emotional Intelligence. Bantam Books, New York, NY.

Goleman, D. (1998, November). What makes a leader? Harvard Business Review, pp. 93-102.

Gronn, P. (2002). Distributed leadership as a unit of analysis. The Leadership Quarterly, 13(4), 423-451.

Hair, J.F., Sarstedt, M., Pieper, T., \& Ringle, C.M. (2012). The use of partial least squares structural equation modeling in strategic management research: A review of past practices and recommendations for future applications. Long Range Planning, 45(5-6), 320-340.

Hiller, N.J., Day, D.V., \& Vance, R.J. (2006). Collective enactment of leadership roles and team effectiveness: A field study. Leadership Quarterly, 17(4), 387-397.

Hollander, E.P. (1974). Processes of leadership emergence. Journal of Contemporary Business, 3(4), 1933.

Hollander, E.P. (1992). Leadership, followership, self, and others. Leadership Quarterly, (1), 43-54.

Ilies, R., Gerhardt, M.W., \& Le, H. (2004). Individual differences in leadership emergence: Integrating meta-analytic findings and behavioral genetics estimates. International Journal of Selection and Assessment, 12(3), 207-219.

Jones, G.R., \& Gorge, J.M. (1998). Contemporary Management. McGraw Hill, New York, NY.

Jordan, P.J., Ashkanasy, N.M., Hartel, C.E.J., \& Hooper, G.S. (2002). Workgroup emotional intelligence: Scale development and relationship to team process effectiveness and goal focus. Human Resource Management Review, 12(2), 195-214.

Judge, T.A., Bono, J.E., Ilies, R., \& Gerhardt, M.W. (2002). Personality and leadership: A and quantitative review. Journal of Applied Psychology, 87(4), 765-780. 
Judge, T.A., Colbert, A.E., \& Ilies, R. (2004). Intelligence and leadership: A quantitative review and test of theoretical propositions. Journal of Applied Psychology, 89(3), 542-552.

Kaiser, R.B., Hogan, R., \& Craig, S.B. (2008). Leadership and the fate of organizations. The American Psychologist, 63, 96-110.

Kellett, J.B., Humphrey, R.H., \& Sleeth, R.G. (2002). Empathy and complex task performance: Two routes to leadership. Leadership Quarterly, 13, 523-544.

Kellett, J.B., Humphrey, R.H., \& Sleeth, R.G. (2006). Empathy and the emergence of task and relations leaders. Leadership Quarterly, 17, 146-162.

Kent, R.L., \& Moss, S.E. (1990). Self-monitoring as a predictor of leader emergence. Psychological Reports, 66, 875-881.

Kilduff, M., Mehra, A., Gioia, D.A., \& Borgatti, S. (2017). Brokering Trust to Enhance: A SelfMonitoring Approach to Leadership Emergence. In J. Glückler, E.I. Lazega (Eds.), Knowledge and Networks. Knowledge and Space (vol 11). Springer, Cham.

Kim, K., Cundiff, N., \& Choi, B. (2014). The Influence of Emotional Intelligence on Negotiation Outcomes and the Mediation Effect of Rapport: A Structural Equation Modeling Approach. Negotiation Journal, 30(1), 49-68.

Kim, K. (2010). The influence of emotional intelligence on negotiation outcomes and the mediation effect of rapport, strategy, and judgment accuracy. Doctoral Dissertation. Southern Illinois University, Carbondale, IL.

Lord, R.G. (1977). Functional leadership behavior: Measurement and relation to social power and leadership perceptions. Administrative Science Quarterly, 22, 114-133.

Law, K., Wong, C., \& Song, J. (2004). The construct and criterion validity of emotional intelligence and its potential utility for management studies. Journal of Applied Psychology, 89(3), 483-496.

Liu, S., Hu, J., Li, Y., Wang, Z., \& Lin, X. (2014). Examining the cross-level relationship between shared leadership and learning in teams: Evidence from China. Leadership Quarterly, 25(2), 282-295.

Mach, M., Dolan, S., \& Tzafrir, S. (2010). The differential effect of team members' trust on team performance: The mediation role of team cohesion. Journal of Occupational \& Organizational Psychology, 83(3), 771-794.

Mayer, J.D., \& Salovey, P. (1997). What is emotional intelligence? In P. Salovey \& D. Sluyter (Eds.), Emotional Development and Emotional Intelligence: Implications for Educators. New York: Basic Books.

McAllister, D.J. (1995). Affect- and cognition-based trust as foundations for interpersonal cooperation in organizations. Academy of Management Journal, 38, 24-59.

O'Mahony, S., \& Ferraro, F. (2007). The emergence of governance in an open source community. Academy of Management Journal, 50(5), 1079-1106.

Paunova, M. (2015). The emergence of individual and collective leadership in task groups: A matter of achievement and ascription. The Leadership Quarterly, 26(6), 935-957.

Peng, D.X., \& Lai, F. (2012). Using partial least squares in operations management research: A practical guideline and summary of past research. Journal of Operations Management, 30(5), 467-480.

Podsakoff, P.M., \& Organ, D.W. (1986). Self-reports in organizational research: Problems and prospects. Journal of Management, 12(4), 69-82.

Podsakoff, P.M., MacKenzie, S., Podsakoff, N., \& Lee, J. (2003).Common method biases in behavioral research: A critical review of the literature and recommended remedies. Journal of Applied Psychology, 88(5), 879-903.

Salovey, P., \& Mayer, J.D. (1990). Emotional intelligence. Imagination, Cognition, and Personality, 9 , $185-211$.

Seers, A., Keller, T., \& Wilkerson, J.M. (2003). Can Team Members Share Leadership. Shared Leadership: Reframing the Hows and Whys of Leadership. Sage, Thousand Oaks, CA.

Sorrentino, R.M., \& Field, N. (1986). Emergent leadership over time: The functional value of positive motivation. Journal of Personality and Social Psychology, 50(6), 1091. 
Walter, F., Cole, M.S., van der Vegt, G.S., Rubin, R.S., \& Bommer, W.H. (2012). Emotion recognition and emergent leadership: Unraveling mediating mechanisms and boundary conditions. Leadership Quarterly, 23(5), 977-991.

Wolff, S.B., Pescosolido, A.T., \& Druskat, V.U. (2002). Emotional intelligence as the basis of leadership emergence in self-managing teams. Leadership Quarterly, 13(5), 505-522.

Yukl, G. (2013). Leadership in organizations global edition. Pearson Education.

Zaccaro, S.J., Rittman, A.L., \& Marks, M.A. (2001). Team leadership. The Leadership Quarterly, 12(4), 451-483.

Zaccaro, S., Kemp, C., \& Bader, P. (2004). Leader traits and attributes. The Nature of Leadership, 101, 124.

192 Journal of Organizational Psychology Vol. 21(4) 2021 